\section{Revisión preliminar de la OMS sobre la hepatitis $C$}

El descubrimiento del virus de la hepatitis C (VHC) en 1989 concluyó un período de intensa investigación internacional dirigida a identificar el esquivo virus "no-A, no-B", que se había hecho notorio como causa de la hepatitis postransfusional. El VHC no es tan infeccioso como el virus de la hepatitis B y el de la inmunodeficiencia humana (VIH), pero la infección puede volverse crónica en hasta $80 \%$ de los casos y producir secuelas tan graves como la cirrosis y el carcinoma hepatocelular. No obstante, es uno de los agentes patógenos más nocivos para la salud humana y figura entre las causas infecciosas de cáncer conocidas.

Ya que el VHC fue identificado hace relativamente poco tiempo, queda mucho por saber acerca de su prevalencia, incidencia y curso natural, así como de las implicaciones patobiológicas, socioeconómicas y de manejo que representa. Está bien documentada su transmisión por sangre transfundida no tamizada, hipodérmicas compartidas entre toxicómanos y uso de material sin esterilizar o mal esterilizado. Algo menos frecuentes son las formas de transmisión sexual y perinatal y las que derivan de prácticas culturales como circuncisión, tatuaje y otras perforaciones de la piel. De una revisión preliminar de la literatura mundial que ha llevado a cabo la OMS, se desprende que la infección por VHC está extendida por todo el mundo, con excepción de Botswana, Perú y Zambia. Los niveles de prevalencia se han agrupado en cinco grados que van desde $<1 \%$ hasta $>10 \%$. Bolivia se encuentra entre los ocho países del mundo con prevalencias que exceden 10\%. En Brasil estas oscilan entre 2,5 y $4,9 \%$ y en el resto de los países de las Américas, de $<1 \%$ a $2,4 \%$. La OMS estima que alrededor de $3 \%$ de la población mundial está infectada con VHC y hay más de 170 millones de portadores crónicos en riesgo de desarrollar cirrosis o cáncer de hígado. Evidentemente, hay que tomar medidas de prevención frente a este gran problema mundial, teniendo en cuenta que el tratamiento es costoso y poco efectivo, y todavía no hay una vacuna contra la infección. La OMS sugiere que los países se ocupen urgentemente de controlar la sangre y sus derivados; divulgar precauciones universales y técnicas de barrera; esterilizar los materiales que se pueden usar más de una vez; destruir las agujas y jeringas desechables, y promover la educación del público general en cuanto a los riesgos del empleo de material no estéril.

Si usted tiene datos recientes y fidedignos sobre la hepatitis $C$ en su país, póngase en contacto con la División de Enfermedades Emergentes y otras Enfermedades Transmisibles - Vigilancia y Lucha, Formación y Apoyo de Laboratorio (EMC/LTS), OMS, CH-1211 Ginebra, Suiza (fax: +41 2279148 78, correo electrónico: lavanchyd@who.ch). (World Health Organization. Hepatitis C. Wkly Epidemiol Rec 1997;72(10):65-69.)

\section{Enfermedades producidas por radicales libres}

Durante los procesos metabólicos de liberar energía, oxidar compuestos endógenos y detoxificar xenobióticos, el oxígeno se comporta como un aceptor terminal de cuatro electrones y pasa por varias etapas hasta transformarse en agua, que es un producto químico estable. Sin embargo, en condiciones normales la reducción de electrones en el oxígeno es incompleta y se producen productos químicos intermedios, de los cuales los más importantes para la fisiología humana son los radicales hidroxilos y superóxidos (radicales libres derivados del oxígeno), junto con los oxidantes no radicales como el peróxido de hidrógeno y el ácido hipocloroso. Un radical libre (RL) es una molécula, átomo o fragmento molecular que contiene uno o más electrones no apareados, lo que le permite entrar en la formación de enlaces químicos. Debido a su estructura, los RL son intrínsicamente inestables, reactivos y de vida muy corta. Están presentes tanto en las células de organismos como en el ambiente y a la larga oxidan todos los compuestos biológicos por medio de sus metabolitos reactivos. Causan la oxidación y peroxidación de lípidos, la desnaturalización de proteínas y la despolimerización de polisacáridos. Los RL alteran el ADN, rompen las membranas celulares, inactivan enzimas, interfieren con la inmunogenicidad y provocan carcinogénesis. En relación con las enfermedades, los RL son liberados durante la inflamación, isquemia o hipoxia de los tejidos.

Los RL son útiles contra bacterias y virus, pero actúan sobre el organismo aun después de haber concluido sus funciones en el metabolismo normal y en la lucha contra las infecciones. Por otra 
parte, el exceso de RL se neutraliza gracias a los mecanismos de defensa naturales del cuerpo, por ejemplo, la generación de enzimas oxidorreductasas como superóxido dismutasa, catalasa y peroxidasa. Si la concentración de estas enzimas es insuficiente, entran en juego los "barredores" antioxidantes no enzimáticos presentes en el cuerpo: betacaroteno, vitaminas A, E y C, cisteína, metionina, tirosina, selenio, ácido úrico, transferrina, cobre, cinc y manganeso. En un organismo saludable hay un buen equilibrio molecular entre la generación de RL y de sustancias protectoras, pero si la balanza se inclina a favor de los radicales libres, los daños generales por oxidación llevan a envejecimiento prematuro, cataratas, carcinogénesis y aterosclerosis. A su vez, esta última provoca hipertensión, angina, isquemia, accidentes cerebrovasculares y otros problemas. Las situaciones que estimulan la producción excesiva de RL son el tabaquismo y alcoholismo; la contaminación atmosférica por carcinógenos y mutágenos; insecticidas y herbicidas; la exposición excesiva a rayos ultravioleta, a reactores y a desastres nucleares; los agentes químicos para procesar alimentos, y los medicamentos anticancerosos. También desempeña un papel decisivo la "contaminación mental", es decir los pensamientos negativos que nacen de los celos, la ira, la avaricia y el odio. Otros efectos deletéreos se deben a estrés emocional o causado por el dolor (con aumento de glucocorticoides y catecolaminas) y al uso de ciertos medicamentos, por ejemplo antiangina. Entre los medios farmacológicos de combatir esos efectos cabe mencionar la nutrición clínica aplicada, terapia de oxígeno hiperbárico y deferroxamina, ácido edético (quelante de $\mathrm{RL}$ ), enzima superóxido dismutasa, vitaminas $\mathrm{A}, \mathrm{C}$ y E, alopurinol (inhibidor de la xantina oxidasa), dimetilsulfóxido y ditiotreitol (eficaces contra los daños producidos en los tejidos por radiactividad), bloqueadores de la vía del calcio como nifepidina y verapamil, inhibidores de la enzima conversora de la angiotensina (ACE) como el captopril, y el vasodilatador pentoxifilina. Entre los medios no farmacológicos más efectivos deben considerarse el cese del consumo de tabaco y alcohol; el inicio de ejercicio físico, yoga y meditación trascendental (producen superóxido dismutasa y disminución de los $\mathrm{RL})$; y el consumo de suplementos nutricionales (ricos en vitaminas y minerales). (Ansari KU. Free radical induced diseases. J Indian Med Assoc 1996; 94(6):238-239.)

\section{Para el año 2020 habrá el doble de discapacidad visual}

Expertos de la Organización Mundial de la Salud indicaron recientemente que en los próximos
25 años puede esperarse un aumento considerable de la ceguera y la discapacidad visual grave, que ya constituyen un importante problema de salud pública. La situación constituirá una carga socioeconómica de alcance universal y un impedimento al progreso de algunos países de ingresos medianos y bajos. Como resultado de las reuniones celebradas en Ginebra a fines de febrero de 1997 por el Grupo Asesor de la OMS sobre la Prevención de la Ceguera y el Comité de Asociación de Organizaciones de Desarrollo no Gubernamentales dedicadas a la Prevención de la Ceguera y a la Educación y Rehabilitación de los Ciegos, se ha recomendado lanzar una nueva iniciativa mundial coordinada por la OMS con el fin de aunar los esfuerzos de organismos internacionales, gobiernos, organizaciones no gubernamentales de desarrollo e industrias en una lucha sostenida contra la ceguera.

Existe una red de cerca de 50 organizaciones de desarrollo no gubernamentales que actualmente invierten unos US\$ 80 millones al año en la lucha contra los trastornos visuales y la ceguera. La red desea movilizar recursos adicionales, ya que esa cantidad no es suficiente para hacer frente al problema. Hoy día casi 150 millones de personas sufren trastornos graves de la visión y 38 millones de ellos están ciegos. Los expertos de la OMS declararon que más de dos terceras partes de esos trastornos podrían haberse evitado con intervenciones preventivas o tratamientos oportunos y adecuados. Todos los años pierden la visión 7 millones de personas, pero más de $70 \%$ de ellas reciben tratamientos que les devuelven esa capacidad. El número de personas ciegas en el mundo aumenta anualmente en incrementos de alrededor de $2 \mathrm{mi}-$ llones. De estos nuevos casos, $80 \%$ se deben a trastornos del envejecimiento. Según las tendencias demográficas, para el año 2020 el número de personas mayores de 60 años casi se habrá doblado y llegará a alrededor de 1,2 billones. Se cree, por lo tanto, que para ese tiempo habrá alrededor de 54 millones de personas ciegas mayores de 60 años, más de 50 millones de ellas en países en desarrollo. El total de personas ciegas en otros grupos de edad excederá de los 21 millones.

Entre las causas principales de ceguera y discapacidad visual relacionadas con la edad figuran las cataratas (a las que se deben 16 millones de ciegos), glaucoma (5,2 millones) y retinopatía diabética (cerca de 2 millones). Estas enfermedades han sobrepasado el tracoma, la xeroftalmía y la oncocerciasis, que se han reducido pero persisten aún como causas importantes de ceguera prevenible en algunos lugares del mundo. Debido a la transición demográfica, para 2020 tanto la carga de esas enfermedades como la demanda de servicios habrán aumentado en términos absolutos. Con el aumento 
de la demanda y la introducción de nuevas tecnologías también habrán aumentado los precios de los servicios. Los participantes en las reuniones antes mencionadas hicieron hincapié en que las intervenciones preventivas ahorran dinero a la larga, pues evitan los gastos de rehabilitación mientras que aumentan la productividad. Son oportunidades de inversión que rinden ganancias económicas y humanitarias. (Organización Mundial de la Salud. WHO sounds the alarm: visual disability to double by 2020. Comunicado de prensa WHO/15, 21 de febrero de 1997.)

\section{Se evalúan los indicadores clínicos de enfermedad pediátrica grave}

Con objeto de reducir la morbilidad y mortalidad de niños pequeños en el mundo en desarrollo, la OMS ha elaborado un algoritmo de diagnóstico y tratamiento que se centra en las causas principales de muerte: infecciones respiratorias agudas, paludismo, sarampión, enfermedades diarreicas y malnutrición. Con este algoritmo de cuadros sobre las enfermedades infantiles, los trabajadores de salud del primer nivel pueden examinar e identificar rápidamente a los niños gravemente enfermos según muestren o no la presencia de 13 signos indicadores de enfermedad grave y enviarlos en seguida a recibir atención intensiva. Los signos son: incapacidad para beber, estado mental anormal (somnolencia excesiva), convulsiones, emaciación, edema, tiraje, estridor, turgencia anormal de la piel, vómitos frecuentes, rigidez del cuello, hinchazón con dolor detrás de las orejas, palidez de la conjuntiva y ulceración de la córnea. Estos signos no se concentran en una sola enfermedad, teniendo en cuenta que a menudo los niños sufren múltiples procesos de enfermedad a la misma vez.

En 1993 se llevó a cabo un estudio de evaluación de la utilidad de estos signos en cuatro clínicas y en el departamento de atención externa de un hospital de distrito en una zona rural de la parte occidental de Kenya. Se adiestró por varias semanas a un grupo de trabajadores de salud potenciales que habían cursado escuela secundaria a tomar una historia clínica sencilla de cada paciente, examinarlo y emitir un diagnóstico. Cada niño ( $n=1262$, mediana de edad 11 meses) fue examinado independientemente por un médico o paramédico que no había sido capacitado en el uso del algoritmo. El médico tomó las decisiones finales de diagnóstico y tratamiento. Se encontró que $27 \%$ de los niños atendidos en clínicas para pacientes externos tenían uno o más de esos signos y que la palidez de la conjuntiva y el tiraje eran los signos asociados más frecuentemente con la hospitalización (OR $=8,6$ y 5,3, respectiva- mente). La presencia de alguno de esos signos aumentó 3,2 veces la probabilidad de ser internado, si bien $54 \%$ de los niños hospitalizados no tenían esos signos mientras que $21 \%$ de los que fueron enviados de vuelta a sus hogares tenían por lo menos uno. Entre los pacientes hospitalizados, 58\% de todos los niños y $89 \%$ de los que habían fallecido habían tenido un signo cuando fueron admitidos. El estado mental anormal fue el signo más frecuentemente asociado con la muerte $(\mathrm{OR}=59,6)$, seguido del de turgencia anormal de la piel $(\mathrm{OR}=5,6)$, palidez conjuntival $(\mathrm{OR}=4,3)$, vómitos frecuentes $(\mathrm{OR}=$ $3,6)$, tiraje $(\mathrm{OR}=2,7)$ y edema $(\mathrm{OR}=2,4)$. En general, el riesgo de morir asociado con la presencia de por lo menos un signo fue 6,5 veces mayor que en otros niños que no tuvieron ninguno de los signos.

El estudio mostró que el algoritmo es útil para identificar a un subgrupo de niños en alto riesgo de muerte mediante la aplicación de un enfoque estándar de diagnóstico, pero tiene que ser validado en otros lugares. Mientras tanto, debe otorgarse prioridad al adiestramiento y la supervisión de trabajadores de salud de atención primaria para que aprendan a reconocer con facilidad a los niños gravemente enfermos. (Paxton LA, et al. An evaluation of clinical indicators for severe pediatric illness. Bull World Health Organ 1996;74(6):613-618.)

\section{Factores de riesgo de intoxicación digitálica}

Con el envejecimiento gradual de las poblaciones y el aumento concomitante de dolencias crónicas de origen cardíaco, es cada vez más común el empleo de glucósidos digitálicos como la digoxina. Este, sin embargo, es un medicamento cuya administración tiene que controlarse cuidadosamente según las necesidades del paciente debido a la frecuencia de intoxicación digitálica. Esta puede producirse no solo por la dosis, sino también por su interacción con muchos otros medicamentos y sus características individuales. En La Habana, Cuba, la tasa estimada de intoxicación es de 9,65 por cada 100 pacientes. Con el fin de profundizar en los factores que propician la intoxicación y en último término prevenirla, se realizó en esa ciudad un estudio de casos y controles basado en una población de referencia de 27571 personas mayores de 15 años que recibían digoxina durante 1992. Por muestreo de conglomerados bietápicos y selección aleatoria se eligieron 30 farmacias y en cada una 35 pacientes registrados como consumidores de digoxina. Los casos fueron 113 pacientes que durante el año de tratamiento presentaron síntomas clínicos y electrocardiográficos atribuibles a intoxicación digitálica confirmada por su médico. En los controles se incluyeron 922 pacientes que no tuvieron esos síntomas o 
que mencionaron algún síntoma no confirmado. Se entrevistó directamente a los pacientes para evaluar las variables de interés: edad de $<80$ o $\geq 80$ años; sexo; peso/talla; dosis de digoxina; uso de diuréticos y suplementos de potasio; enfermedades asociadas; medicamentos asociados; hábitos tóxicos (café, tabaco, alcohol), y antecedentes de intoxicación digitálica. Se encontró una asociación significativa $(\mathrm{P}<0,01)$ entre la intoxicación y tener $\geq 80$ años; tomar dosis altas; bajo peso para la talla; no ingerir suplementos de potasio; padecer enfisema pulmonar obstructiva crónica (EPOC), insuficiencia respiratoria crónica (IRC) o anemia; tomar medicamentos asociados como furosemida, tiazidas, dipiridamol, amiodarona, quinidina, nifedipina o verapamilo; antecedentes de intoxicación digitálica; hábito de fumar, y alcoholismo. Se observó un efecto muy marcado en el uso de quinidina, antecedentes de ID y el uso de algún diurético, y menos marcado en ser bajo de peso para la talla, recibir dosis altas de digoxina, usar verapamilo y padecer IRC. El resto de las variables tuvieron un efecto menos intenso.

No obstante la frecuencia de varios grados de intoxicación, es evidente que los medicamentos digitálicos han resistido la prueba del tiempo y continuarán siendo útiles, especialmente si se tienen en cuenta los factores expuestos, para prevenirlos. (Sánchez de la Rosa R, et al. Aportes en la vigilancia epidemiológica de los pacientes tratados con digoxina. Arch Inst Cardiol Mex 1996;66(6):510-518.)

\section{Epidemia de enfermedades de transmisión sexual en Europa}

Durante el período de 1980 a 1991 disminuyó en Europa occidental la incidencia de sífilis y gonorrea, pero desde 1991 en adelante han aumentado aceleradamente las enfermedades de transmisión sexual (ETS), especialmente la sífilis, en los nuevos Estados independientes de la Europa oriental. En la Federación de Rusia, por ejemplo, se registró una incidencia de 86 por 100000 habitantes en 1994 y de 172,1 en 1995, lo que representa 40 veces la cifra de 1989. En otros países de la antigua URSS el aumento es de 15 a 30 veces las cifras anteriores, con inciden- cias que de 1990 a 1995 han aumentado desde 5 a 15 casos por 100000 habitantes hasta 120 a 170 por 100 000. Como en otras situaciones de salud, este alarmante cambio se debe, en último término, a razones sociales y económicas. En países como Belarús, Moldova y Ucrania, la transición a un sistema de economía de mercado ha sido agitada y ha habido una continua disminución del ingreso que se refleja en desempleo, prostitución y drogadicción. En gran parte de esa zona se observan inestabilidad y desorganización de la infraestructura social; conflictos armados y problemas étnicos; migración activa y gran número de refugiados y personas sin hogar ni empleo. Todos estos factores tienen efectos muy negativos en las enfermedades "sociales" como la tuberculosis, los trastornos psiquiátricos y las ETS. Estas últimas enfermedades en particular tienen consecuencias graves para la salud reproductiva y de los neonatos. Además, son factores de riesgo en la transmisión del VIH.

La Oficina Regional de la OMS para Europa ha reunido a grupos de asesores expertos para debatir el problema y, teniendo en cuenta la información obtenida, recomienda una serie de acciones que son de interés también para los países de otras regiones: prevención de las ETS y promoción simultánea de la salud sexual; servicios clínicos más flexibles y baratos, incluso en condiciones de anonimato, para pacientes ambulatorios; manejo de las ETS por personas no especialistas; búsqueda activa y tamizaje confidencial de casos, y vigilancia centinela en las clínicas. Asimismo es necesario abrir las líneas de comunicación entre profesionales de la salud y de otras disciplinas, organizaciones gubernamentales y no gubernamentales y el público en general, y los grupos en riesgo especial. Las leyes actuales sobre el control de ETS no ayudan a controlar las epidemias; deben ser menos opresivas y proteger los derechos individuales de los enfermos. Por último, los países que tienen experiencia en esta materia deben compartir sus conocimientos con otros, quizá por medio de una entidad regional patrocinada por una organización de salud internacional. (Gromyko AI. Sexually transmitted diseases (STDs) epidemic in eastern Europe: a call for help! Entre Nous: The European Family Planning Magazine 1996;33(September):7-8.) 